\title{
PERMANENT MAGNET AIR-CORED TUBULAR LINEAR GENERATOR FOR MARINE ENERGY CONVERTERS
}

\author{
N. J. Baker (1), M. A. Mueller(2), \& E. Spooner(1) \\ 1. University of Durham, UK. 2. University of Edinburgh, UK. \\ Markus.Mueller@ed.ac.uk \\ Fax: 01316506554
}

Keywords: Air-cored, PM machines, tubular, marine renewable energy

Abstract

In this paper the authors outline the performance and modelling of a prototype linear tubular permanent magnet machine with an air cored stator. The main application of the machine is in direct drive marine energy conversion systems, where speeds are typically in the region of $0.5 \mathrm{~m} / \mathrm{s}$. A simple analytical method was derived to provide an initial design of a prototype machine, which was then modelled using $2 \mathrm{D}$ axisymmetric finite element analysis. Experimental results are presented to verify the design, and to investigate the performance of the machine as a generator.

\section{Introduction}

Exploiting the vast energy source contained in the ocean has been of interest for almost 30 years in the UK. Many years of research, in combination with the recent success of offshore wind energy and desire for renewable energy in general, has culminated in research aiming to hamess the power from the ocean being more intensive and closer to commercialisation than ever before. Several companies are deploying prototype and full scale test plants in the ocean. The two areas of marine energy undergoing development are wave energy and tidal stream energy. Many of these devices produce linear low speed reciprocating motion with a peak speed of less than 2 $\mathrm{m} / \mathrm{s}$, which must subsequently be converted into electrical energy. Developers propose using conventional induction generators to produce electrical power, but as a result require a mechanical interface such as a hydraulic system to match the low speed reciprocating motion to high speed rotary motion [1\&2].

Direct drive electrical power take off systems could replace hydraulics, resulting in a much simpler form of power take off. A prototype linear PM synchronous generator has been designed and built for a seabed mounted wave energy converter, the Archimedes Wave Swing [3]. This device is rated at $2 \mathrm{MW}$, but with an average rating of only $400 \mathrm{~kW}$. This machine is over $10 \mathrm{~m}$ in length, and there are significant mechanical engineering challenges to overcome. In order to reduce the physical size of linear generators for Marine Energy Converters (MECs) high shear stress machines, such as the Transverse Flux Machine (TFM) and its variant the Vernier Hybrid Machine (VHM) have been investigated
[4\&5]. The TFM is more difficult to construct than the VHM, but both require significant support structures to overcome the large magnetic forces that exist between the stator and translator. Innovative lubrication systems are required to maintain the airgap. In addition both suffer from low power factor [6\&7].

In this paper a machine topology is investigated which overcomes both the mechanical and power factor issues. The topology of machine is introduced and put into the context of similar machines. For completeness sake brief information is given on the method of design of this machine in the synopsis, but more detailed analysis is published in [9]. In this paper a finite element model of the machine is presented, which is then verified using experimental results.

\section{Tubular machine}

In a brushless PM machine, stationary copper coils surround a magnetised tubular translator. The active part of the translator consists of a series of steel pole pieces sandwiched between permanent magnets such as neodymium-iron-boron. Magnetisation of the magnets is axial and they are mounted such that the steel pieces act as flux concentrators to form alternate North and South surface poles. The magnet driven field hence follows the movement of the translator, resulting in a moving magnetic freld passing through the coils. Stator coils are supported within either an internal/external sleeves, or placed in actual slots. The design and optimisation of these iron cored versions of these machines has been published in [8].

To extract significant amounts of power at the low velocities found in MECs requires large reactive forces and hence large electrical machines. In a large linear machine, however, the strong magnetic field results in a significant force of attraction between the translator and stator. This must be withstood by the mechanical structure and lubrication system. Significant structural savings can be made if the magnetic forces can be reduced or eliminated, which can be achieved by constructing a stator which contains no iron. These features are demonstrated in Figure 1. As shown, the translator consists of opposed axially magnetised PMs separated by steel spacers, both mounted on a non magnetic shaft. This configuration, assuming that the iron does not saturate, results in the residual translator forces being 
attractive. Without the spacers, strong repellent forces would be present. Radially magnetised or surface mounted magnets may prove more attractive for large diameters, but at this scale represent a more difficult structure to manufacture.

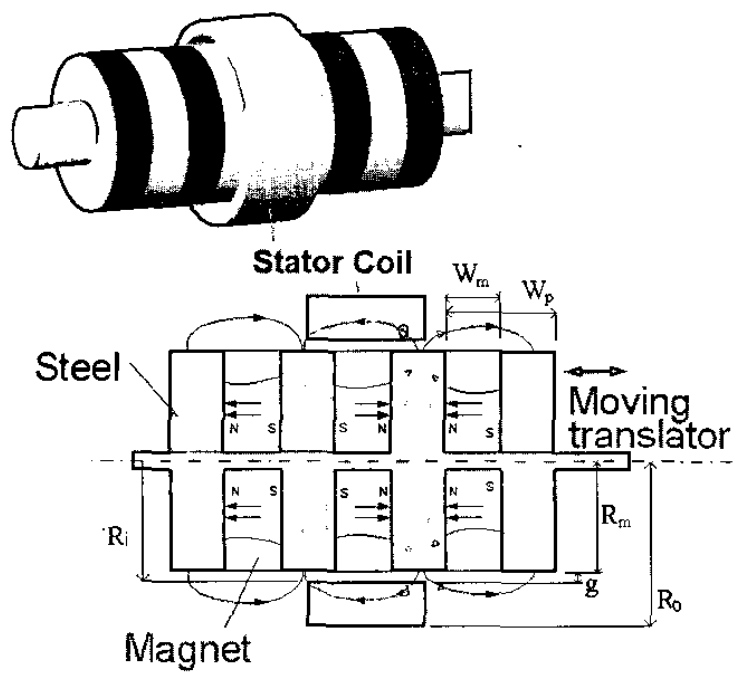

Figure 1:General layout of topology

\section{Design of the air-cored PM tubular machine}

A similar design with an iron core has been both analysed and optimised [8], which provides some relevant results. Using the notations given in Figure 1 and assuming that the airgap, $\mathrm{g}$, is a specified design parameter restricted to its minimum obtainable size, there are three dimensional ratios which may be considered: $w_{m} / W_{p}, R_{m} / R_{0}$ and $w_{m} / R_{0}$. The first of these, which for a given magnet width specifies the width of steel spacer, is said to behave independently and not influence the choice for the other two [8]. The choice of $W_{p}$ is, by implication, not affected by the lack of iron in the stator, which effectively sets $R_{o}$ to infinity. Within that research it was concluded that the value $w_{m} / W_{p}$ should be set for the condition of minimum torque ripple and a value of 0.5 to 0.7 was recommended accordingly [8].

The shear stress for this machine has been derived in [9] and is given by equation 2 .

$$
\begin{aligned}
& \bar{\sigma}=\frac{\mathrm{J}_{\mathrm{e}} \hat{\mathrm{B}}_{\mathrm{g}} \mathrm{l}_{\mathrm{g}}}{\mathrm{R}_{\mathrm{m}}} \frac{\mathrm{w}_{\mathrm{s}}}{\left(\mathrm{w}_{\mathrm{m}}+\mathrm{w}_{\mathrm{s}}\right)} \mathrm{e}^{-\mathrm{g} / \mathrm{I}_{\mathrm{s}}}
\end{aligned}
$$

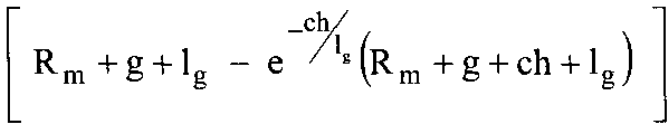

$$
\begin{array}{lll}
\mathrm{g} & = & \text { physical airgap clearance }(\mathrm{m}) \\
\mathrm{ch} & = & \text { coil height }(\mathrm{m}) \\
\mathrm{R}_{\mathrm{i}} & = & \text { inside radius of coil }(\mathrm{m})=\mathrm{R}_{\mathrm{m}}+\mathrm{g} \\
\mathrm{R}_{0} & = & \text { outside radius of coil }(\mathrm{m})=\mathrm{R}_{\mathrm{m}}+\mathrm{g}+\mathrm{ch}, \\
\mathrm{R}_{\mathrm{m}} & = & \text { radius of magnets }(\mathrm{m}) \\
\mathrm{J}_{\mathrm{e}} & = & \text { equivalent current density }\left(\mathrm{A} / \mathrm{m}^{2}\right) \\
\hat{B}_{g} & = & \text { peak flux density at pole surface } \\
\mathrm{l}_{\mathrm{g}} & = & \text { equivalent airgap }(\mathrm{m}) \\
\mathrm{Ws} & = & \text { width of steel }(\mathrm{m})
\end{array}
$$

The equivalent airgap, $l_{g}$, derived in [9], is defined as the equivalent gap in an iron-core machine that would produce the same peak flux density at the pole surface as in an aircored machine (equation 3 ).

$l_{g}=\frac{w_{m}+w_{s}}{\pi}$

The flux density decays exponentially from the translator surface. There is hence a limit to the coil height, ch, which interacts with the translator flux and thus contributes to the useful reaction force. Setting ch to equal twice $l_{g}$ ensures $90 \%$ of the translator flux is utilised. Equation (3) shows the value of $l_{g}$ to be dependent on the pole width of the translator and hence vary with the width of steel for a given magnet piece. To allow investigation, the width of spacer is nominally taken to be equal to the magnet width in accordance with [8]. These two conditions combined give a general equation for the shear stress as in (4).

$$
\left.\bar{\sigma}=\frac{\mathrm{J}_{\mathrm{e}} \hat{\mathrm{g}}_{\mathrm{g}} \mathrm{w}_{\mathrm{m}} \mathrm{e}^{\frac{\mathrm{g} \pi}{2 \mathrm{w}_{\mathrm{m}}}}}{\pi \mathrm{R}_{\mathrm{m}}}\left(0.865 \mathrm{R}_{\mathrm{m}}+\mathrm{g}\right)+1.188 \frac{\mathrm{w}_{\mathrm{m}}}{\pi}\right)
$$

Magnets of $100 \mathrm{~mm}$ diameter were readily available from the manufacturer, but for ease of cutting the thickness was limited to $25 \mathrm{~mm}$ and a steel section of the same width was used. The basic geometrical data of the prototype is given in Table $1 \&$ Figure 2.

Table 1: Dimensions of tubular prototype

\begin{tabular}{|l|l|}
\hline Magnet width & $0.025 \mathrm{~m}$ \\
\hline Steel Width & $0.025 \mathrm{~m}$ \\
\hline Translator diameter & $0.1 \mathrm{~m}$ \\
\hline Shaft diameter & $0.02 \mathrm{~m}$ \\
\hline Airgap & $0.005 \mathrm{~m}$ \\
\hline Velocity & $0.5 \mathrm{~m} / \mathrm{s}$ \\
\hline
\end{tabular}

Where 


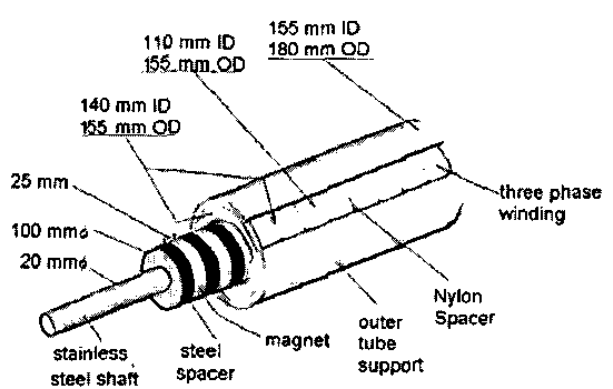

Figure 2: Dimensions of one half of the prototype

The peak flux density at the surface of the translator, $\hat{B}_{g}$, may be found by the use of a simple equivalent magnetic circuit. Figure 3 shows the assumed flux flow, including leakage through the central stainless steel support, and corresponding equivalent circuit.
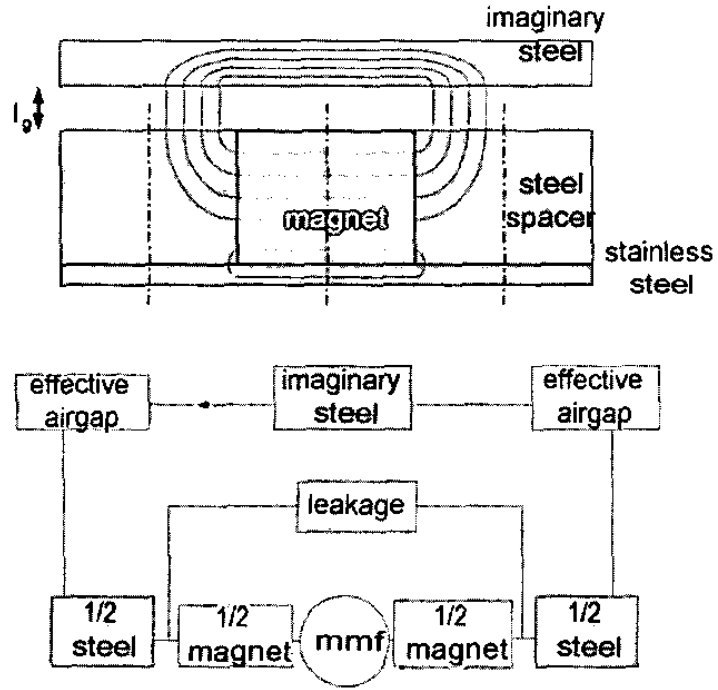

Figure 3: Assumed flux flow and equivalent reluctance network of translator.

By analysing the magnetic circuit the peak flux density at the surface of the translator was calculated to be $0.628 \mathrm{~T}$.

The dimensions of the coil are largely predetermined by the size of other components. In order to maximise the emf from the machine, the maximum number of coil turns was strived for. Using $1 \mathrm{~mm}$ diameter wire and a fill factor of 0.54 , the coils, which covered one third of a translator pole each, consisted of 230 turns. For a coil current of $10 \mathrm{~A}$, the equivalent current density of a single coil occupying the same space, $J_{\mathrm{e}}$, is equal to $6.9 \times 10^{6} \mathrm{Am}^{-2}$.
These values may be substituted into equation (4) to give a shear stress of $28 \mathrm{kN} / \mathrm{m}^{2}$. Each coil covers one third of a translator pole, equivalent to an area of $0.0047 \mathrm{~m}^{2}$. Average force per coil is therefore predicted as $130 \mathrm{~N}$. For a machine rated for $3 \mathrm{~kW}$ at $0.5 \mathrm{~m} / \mathrm{s}$, a reactive force of $6 \mathrm{kN}$ is required, corresponding to 46 such coils. A 16 pole stator is hence required.

\section{Finite element model}

\subsection{Introduction}

A 2D axisymmetric finite element (FE) model of the machine was developed using commercial software [10]. Figure 4 shows the flux produced by the tubular PM translator. The FE model was used to determine flux linkage data for induced emf and inductance calculations.

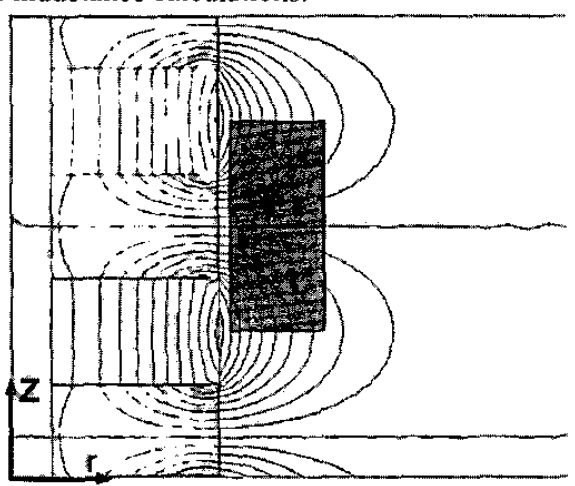

Figure 4: Flux flow due to PM translator

Both axial and radial forces are present in the machine. The former is the thrust force and provides power generation. At translator positions where the PM field acts axially, i.e. in the direction of motion, interaction with circumferential current produces an attractive radial force. Compared to the equivalent attractive force between iron surfaces, this force is an order of magnitude lower. Finite element results for the prototype indicate that this radial force expressed as a stress is equal to $28 \mathrm{kN} / \mathrm{m}^{2}$, compared to $400 \mathrm{kN} / \mathrm{m}^{2}$ for an airgap flux density if $1 \mathrm{~T}$ between two iron surfaces. This clearly justifies the investigation of air core machines in terms of simplified bearing design and reduced mechanical structure.

\subsection{Verification of simple model}

The FE program can be used to generate the constant current force profile as the relative coil and magnet position alters, Figure 5.

The two maxima have slightly different values, implying the magnitude of the force is dependent on the direction of current with respect to the remnance of the magnets. Flux driven by the current can either strengthen or oppose the magnetic field of the stator and the force varies accordingly. 
The RMS value of the $10 \mathrm{~A}$ force curve is $143 \mathrm{~N}$, implying a $9 \%$ error on the simple analytical method of section 3 above.

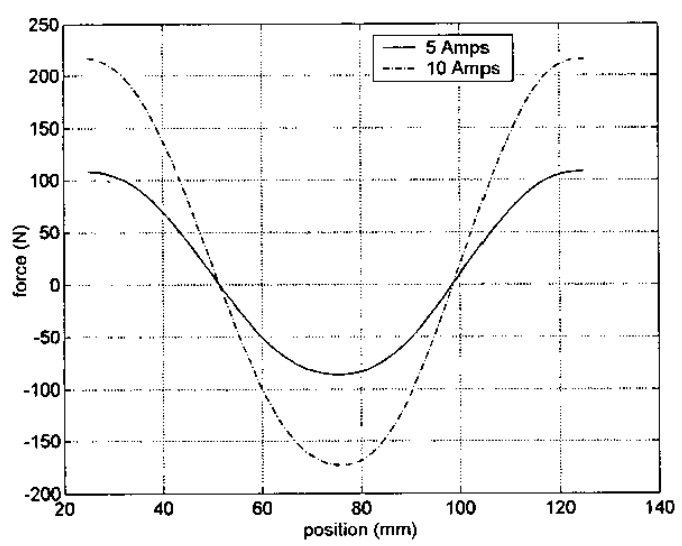

Figure 5: Axial force verses position for constant current

\section{Equivalent circuit model}

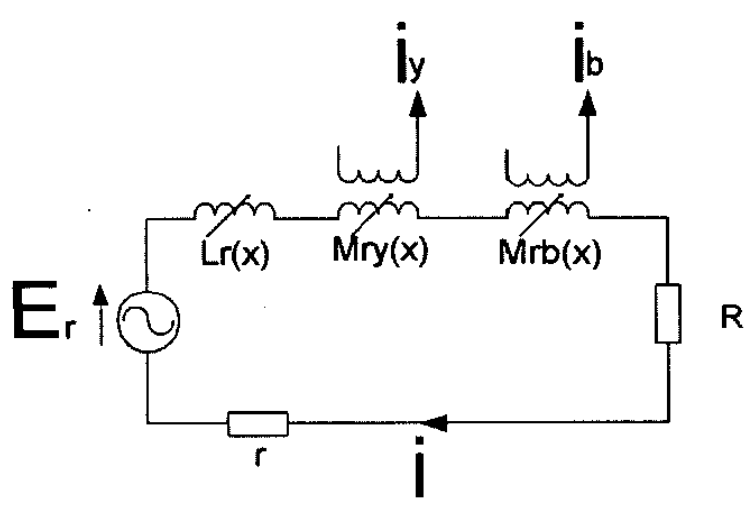

Figure 6: Equivalent circuit of one phase (red)

The predominance of air in the flux retum path implies that the coil inductance is independent of current. Iron pieces in the translator, however, manipulate the flux path slightly such that there is a small variation in coil inductance with translator position, $x$. These two factors imply that the characteristics of a single coil may be modelled as an emf source in series with a position dependent inductor. An entire phase may hence be modelled as the system shown in Figure 6. The presence of coil supports between some coils in the prototype described below gave rise to a slightly unbalanced three phase system. It is hence not possible to make the normal assumptions associated with three phase systems, namely that all mutual inductances are equal and the instantaneous sum of the currents is zero. The voltages in the machine are hence given by (5) and may be solved by expressing them as (6).

$$
\begin{aligned}
& E_{r}=L_{r} \frac{d i_{r}}{d t}+i_{r} \frac{d L_{r}}{d t}+M_{r y} \frac{d i_{y}}{d t}+i_{y} \frac{d M_{r y}}{d t}+M_{r b} \frac{d i_{b}}{d t}+i_{b} \frac{d M_{r b}}{d t}+i_{r}(r+R) \\
& \frac{d i_{r}}{d t}=\left(E_{r}-M_{r} \frac{d i_{y}}{d t}-i_{y} \frac{d M_{r y}}{d t}-M_{r b} \frac{d i_{b}}{d t}-i_{b} \frac{d M_{r b}}{d t}-i_{r}(r+R)\right) \frac{1}{\mathrm{~L}_{r}}
\end{aligned}
$$

The value of induced emf, $\mathrm{E}_{\mathrm{r}}$, is calculated from equation 7 .

$$
\begin{aligned}
& E_{r}=\frac{d \psi_{r}}{d t}=\frac{d \psi_{r}}{d x} \frac{d x}{d t} \\
& \text { Where } \begin{array}{lll}
\mathrm{E}_{\mathrm{r}} & =\quad \text { emf of red phase }
\end{array} \\
& \mathrm{M}_{\mathrm{ry}}=\text { mutual inductance } \mathrm{red} / \mathrm{yellow} \\
& \text { phases, function of } x \\
& \mathrm{x}=\text { position of translator } \\
& \Psi_{\mathrm{r}} \quad=\quad \text { magnet driven flux linkage } \\
& \text { through red phase }
\end{aligned}
$$

Coefficients for inductance and flux linkage may be calculated from the FE program and are simplified to a set of position dependent Fourier series'. A dynamic SIMULINK model may hence be used to solve the current in (7) and the two similar equations for the remaining phases.

\section{Prototype and test-rig development}

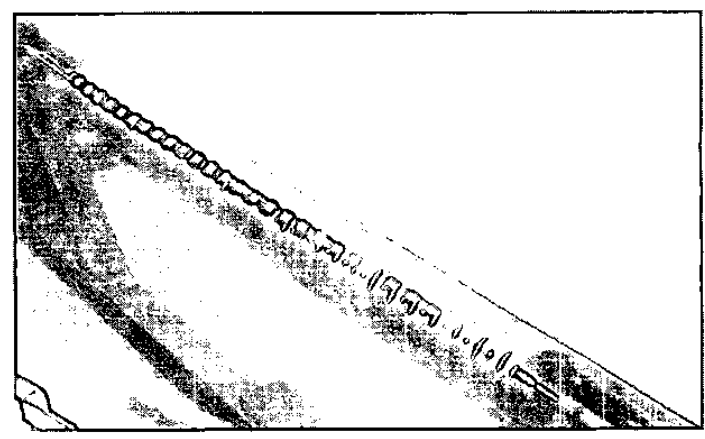

Figure 7: Tubular Machine Translator

Figure 7 shows the PM tubular translator mounted on a stainless steel shaft. The translator is further supported along its length using a solid contact bearing as shown in Figure 8. The stator body consists of a $15 \mathrm{~mm}$ thick plastic tube with the stator coils suspended on the inside. Each individual coil consists of 230 turns of $1 \mathrm{~mm}$ diameter copper wire bound together by glass tape. Every third coil has a $6 \mathrm{~mm}$ nylon spacer mounted to the inside of the tube. The spread of support spacers is such that two of the phases are direct neighbours (red/yellow, yellow/blue) whereas the third (red/blue) is kept $6 \mathrm{~mm}$ apart. The mounting points of the spacer serve to react force from the coils and ensure that the 
three coils represent exactly one translator pole width to ensure a 3-phase output. The tube was secured to an aluminium frame by in-house manufactured brass bolts.

The tubular machine was mounted horizontally and powered by a $225 \mathrm{~mm}$ length crank arm coupled to a 1:40 step down gearbox driven by a two pole induction machine, Figure 9 . Varying the length of crank and motor speed allows the generator to be tested for different peak speeds and oscillation amplitudes.

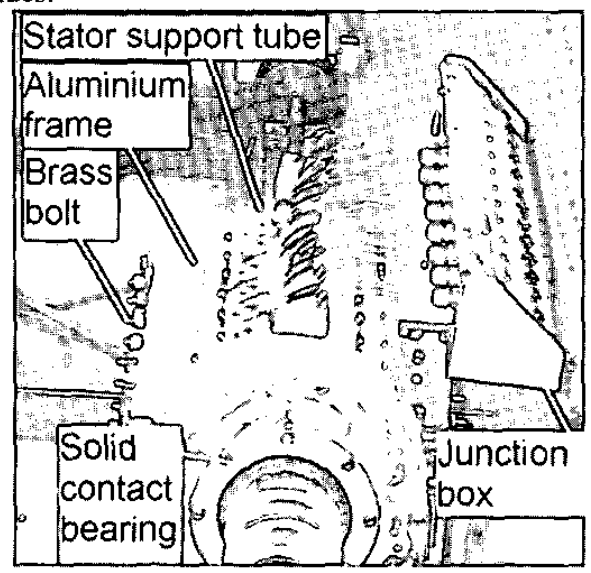

Figure 8: Tubular Machine Prototype

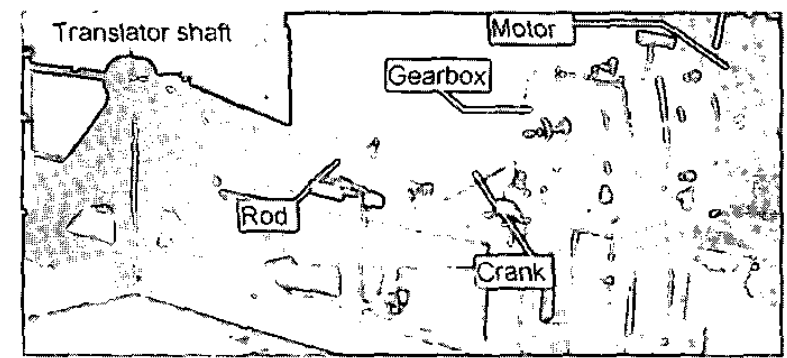

Figure 9: Mechanical excitation of translator

\section{Results}

\subsection{Translator Flux Density}

A Hall probe was used to measure the flux density distribution on the surface of the translator and at various radial positions above it. These results provided verification of the finite element model. Measured and calculated results of radial flux density are shown in Figure 10, from which it can be seen that there is very good correlation.

\section{2 Open Circuit}

Predicted and experimental open circuit voltage for a single coil is shown in Figure 11, showing the model to give a $10 \%$ under estimation of the experimental value. The model assumed a constant angular velocity for the motor driving the testrig. Demonstrated in Figure 11 is the inaccuracy of this assumption, accounting for the drift out of phase at peak amplitudes combined with the coincidence of the positions of zero linear velocity $(t=2.5,3.7,4.9 \mathrm{~s})$.
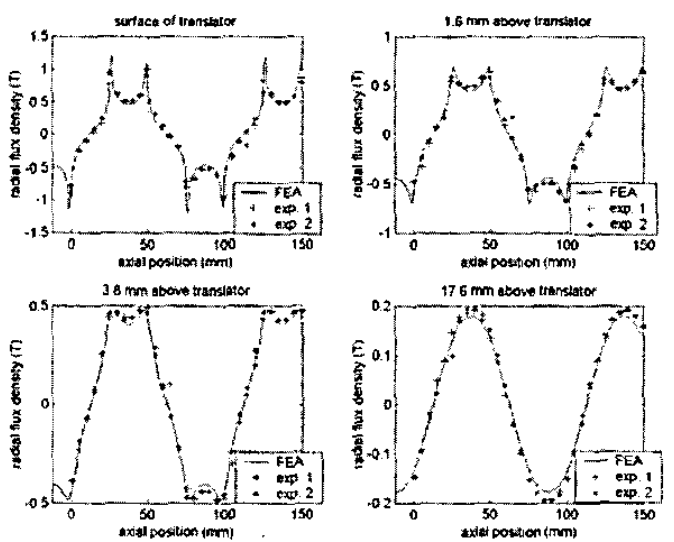

Figure 10: Comparison of actual and predicted radial flux density

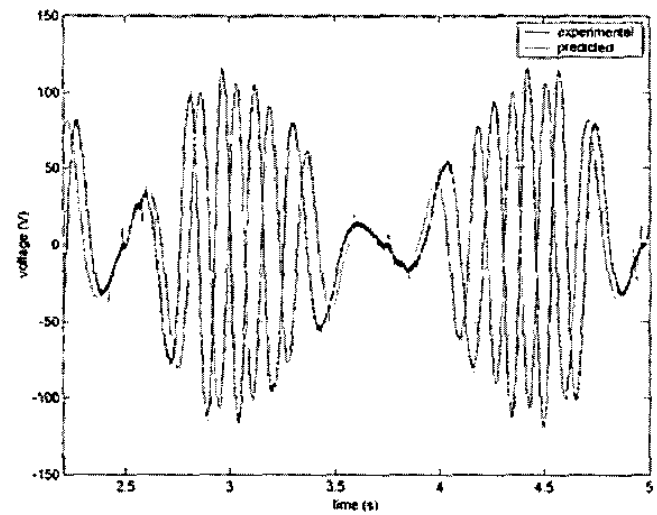

Figure 11: Open circuit results for a single phase

\section{3 Resistive load}

From the maximum power transfer theorem a load resistance was chosen to equal the winding phase resistance, which is equal to just over $16 \mathrm{Ohms}$. Figure 12 shows a comparison of the experimental and predicted voltages of all three phases when the machine is connected to three $17 \Omega$ resistors in star. The general correlation between the two plots is good, with the distribution being accurately predicted. Careful inspection of the graphs highlights the slight imbalance in the three phases. Under load a power factor of greater than 0.95 was measured. 

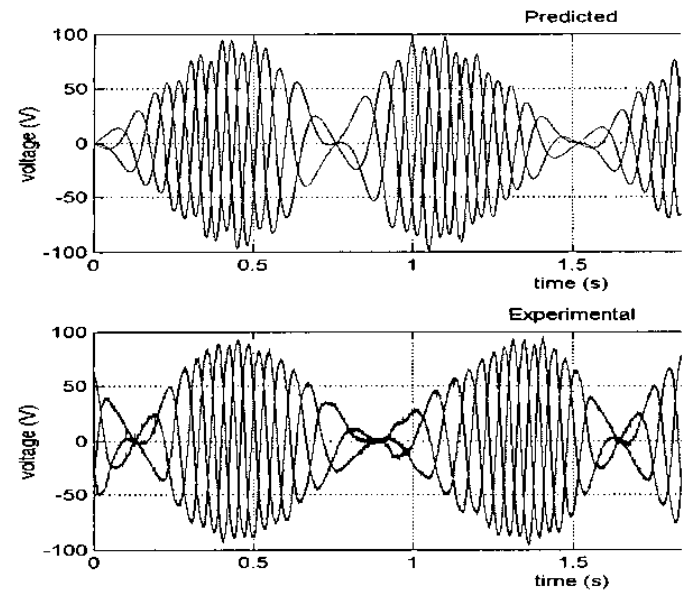

Figure 12: Comparison of predicted and experimental voltage for a $17 \Omega$ load

\section{Application to MECs}

In MECs the velocity of the prime mover is in the region of 0.5 to $1 \mathrm{~m} / \mathrm{s}$, orders of magnitude lower than the velocity found in conventional rotary machines. Direct drive machines are therefore expected to be very large, resulting in significant mechanical design challenges, such as the method of lubrication, to integrate such machines into a wave energy converter. High shear stress machines such as the TFM would appear to offer a solution to the physical size, but such machines suffer high attractive magnetic forces. These forces place severe constraints on the lubrication system and the support structure. In addition they suffer from low power factor. The air-cored PM tubular machine topology presented in this paper does not suffer from such large magnetic attraction forces and exhibits a very high power factor. Furthermore, its tubular cross section enables the use of more conventional sealing systems when compared to the planar cross-section of a TFM, which does not lend itself to sealing. The issue of lubrication has not disappeared with the tubular machine, but the forces involved are not as great. One option is to flood the machine so that the airgap becomes a fluid bearing. In flooding the machine there is no longer a need to provide tight sealing. A suitable coating would be required to prevent corrosion of the generator. With this application an integrated design approach is required. Hence although the air-cored tubular machine does not exhibit a high shear stress compared to the TFM say, its simpler mechanical construction has potential benefits in the mechanical integration of linear machines into marine energy converters.

As can be seen from the waveforms in figure 12 power conditioning is required before the generator is connected to the grid. This is true regardless of the topology of machine used. However in machines similar to the TFM the converter used will be of a much higher rating compared to the aircored machine due to the low power factor. For a TFM an active rectifier would be required to extract maximum power, whereas in the air-cored machine a simple rectifier could be used to feed the dc link of the power converter.

\section{Conclusion}

The design and modelling of an air-cored PM tubular machine has been presented. An expression for shear stress has been verified, which can be used with confidence for machine sizing. A more detailed finite element model has been experimentally verified under both no-load and load conditions. Even though the air-cored tubular machine exhibits low shear stress it offers potential benefits in terms of mechanical construction and a significantly higher power factor.

\section{Acknowledgements}

The authors would like to thank Durham University for providing facilities and the EPSRC for funding (Grant no. 38299)

\section{References:}

1. YEMM R.W., HENDERSON R.M., \& TAYLOR C.A.E., ' The OPD Pelamis: Current Status and Onward Programme', Proc. of the $4^{\text {th }}$ European Wave Energy Conference, Denmark, 2000.

2. TRAPP A.D. \& WATCHORN M., 'EB development of tidal stream energy', Proceedings of the Marine Renewable Energy Conference, Newcastle, March 2001.

3. POLINDER H., GARDNER F., \& VRIESMA B., ' Linear PM generator for wave energy conversion in the AWS', Proc. of the International Conference on Electrical Machines, Finland, Aug. 2000.

4. MUELLER M.A., 'Electrical generators for direct drive wave energy converters', IEE Proc.-Gener. Transm. Distrib., Vol. 149 , No. 4, July 2002.

5. MUELLER M.A. \& BAKER N.J., ' A low speed reciprocating permanent magnet generator for direct drive wave energy converters', Proceedings of the $1^{\text {st }}$ IEE PEMD Conference, Bath, UK, 2001.

6. HARRIS, M.R., PAJOOMAN G.H., \& ABU SHARKH S.M., 'The problem of power factor in VRPM Transverse Flux Machines', Proc. IEE Int. Conf. on Electrical Machines \& Drives, Cambridge, UK, 1997.

7. SPOONER E. \& HAYDOCK L., 'Vernier Hybrid Machines', IEE Proc. Part B Electric Power Applications, Vol. 150, no. 6, Nov. 2003, pp. 655-662

8. WANG, J., JEWELL, G.W. and HWE, D.: 'Design optimisation and comparison of tubular permanent magnet machine topologies', IEE proc. Electrical power Applications, Vol148, No.5, Sept 2001, pp456-464

9. BAKER N.J., 'Linear Generators for Direct Drive Marine Renewable Energy Converters', PhD Thesis, University of Durham, July 2003.

10. PC-OPERA, Vector Fields Ltd., Oxford, UK. 